\title{
Creation of Virtual Environment with AMESim and its Integration with MATLAB/Simulink
}

\author{
Rafael Luiz da Silva Tovo ${ }^{1}$ \\ Francisco Javier Triveno Vargas ${ }^{2}$ \\ Embraer S.A.-
}

2170 Brigadeiro Faria Lima Avenue,

São Jose dos Campos, SP, Brazil.

Luiz Carlos Sandoval Goes ${ }^{3}$

Aeronautics Institute of Technology- ITA

50 Marechal Eduardo Gomes Square,

São Jose dos Campos, SP, Brazil.

\begin{abstract}
Increasingly, the aviation industry coexists with highly complex and integrated systems, parallel to the search of engineering tools simple to execute and reduce the complexity and effort in modeling systems and provide reliable results through the simulation. Accomplishing this task reduces the demand for time and costs in system modeling. Also, it is desirable to commercially available simulation environments to accomplish these expectations. In this context, this paper aims to integrate the electro-hydrostatic actuator (EHA) whose components are physically modeled in LMS Imagine.Lab AMESim software to MATLAB/Simulink ${ }^{\circledR}$, through s-functions. With the implemented models, simulations are made in both environments; these results provide data for performance comparisons and conclusions about possible gains of this integration. Finally, it is taken advantage of the physical modeling AMESim to linearize a high fidelity model and uses it in linear control projects in MATLAB/Simulink ${ }^{\circledR}$ environment.
\end{abstract}

Keywords. Electro-hydrostatic, Actuator, AMESim, MATLAB/Simulink, Modeling, Simulation.

\section{Introduction}

Historically, many work and research have already been performed with the support of the integration between multiple simulation environments, each one chosen for its particular advantages and characteristics. Examples of such integration, specially the interaction

\footnotetext{
${ }^{1}$ rafael1st@yahoo.com.br,

2 francisco.vargas@embraer.com.br

3 goes@ita.br
} 
between AMESim and Simulink, can be found in many research papers $[1,5,6]$. This paper has the objective of showing an application of this approach.

An electro-hydrostatic (EHA) model is a good system choice for applying this integrated simulation approach, because this system is not too complex, has non-linear characteristics, involves multi-domain and needs some control to work properly.

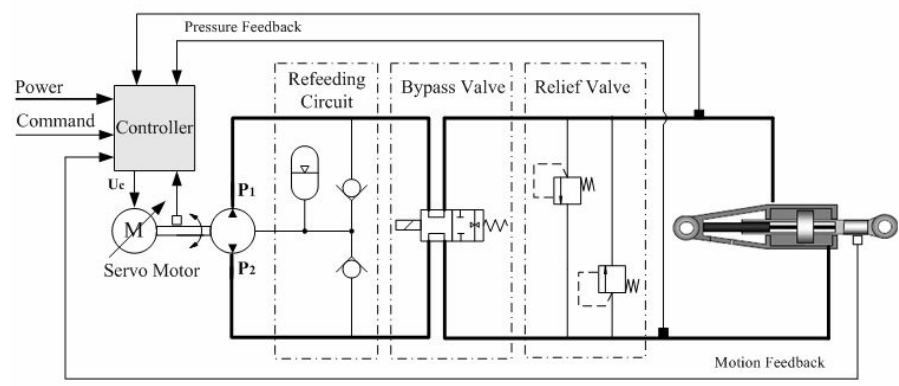

Figure 1: EHA architecture.

\subsection{The Electro-Hydrostatic Actuator (EHA)}

The demand for conventional hydraulic actuation is gradually decreasing due to its limitations, such as: low energy efficiency, leakage, noise, low maintainability. The powerby-wire technology became an attractive option for the present and future of airborne flight control actuation system [2]. The concept of 'more electric aircraft' (MEA) involve simpler, cheaper, lighter and more efficient power generation and distribution architectures. To achieve this goal, power-by-wire actuation has been developed for years in the directions of EHAs. Being well suited to actuation of primary flight surfaces, they are already used on civil and military aircraft flight control, bringing the possibility of eliminating one central hydraulic circuit, while also delivering a fail-safe system with energy, cost and environmental benefits $[3,4,5]$.

\section{Methodology}

This article aims at the four first blocks of the methodology showed in Figure 2.

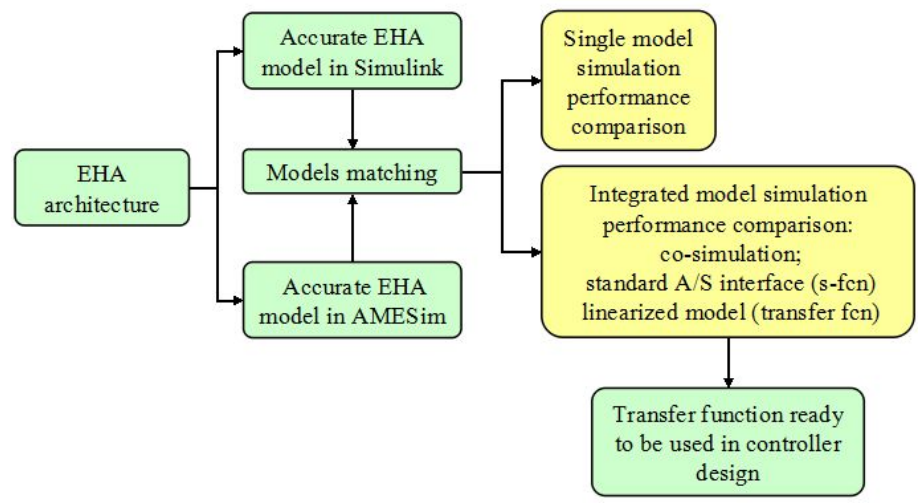

Figure 2: Methodology of EHA models simulation and comparison. 
The following sections bring the equationing and modeling of the main components of the EHA only.

\subsection{Modeling of motor}

The electric motor is a DC permanent magnet brushless. The maximum speed is 12000 $\mathrm{rpm}$, the nominal voltage is $270 \mathrm{~V}$ and nominal power is $10 \mathrm{~kW}$. The equations governing this motor are given by:

$$
\left\{\begin{array}{l}
U_{c}=E+L \frac{d i}{d t}+R i \\
E=K_{c} \omega \\
T_{e}=K_{t} i \\
T_{e}=J \dot{\omega}+K_{\text {fric }} \omega+T_{l}
\end{array}\right.
$$

Where $E$ is the back electromotive force, $L$ is the motor winding inductance, $R$ is the motor winding resistance, $T_{e}$ is the electromagnetism torque, $J$ is the sum of inertia of motor and pump, $K_{\text {fric }}$ is the sum of viscous coefficient of motor and pump, $T_{l}$ is the load torque acting on the motor shaft and $\omega$ is the rotational speed of motor.

\subsection{Modeling of pump}

The pump axis is rigidly connected to the electrical motor axis. The pump is bidirectional and has internal leakage. Its schematic diagram is showed in Figure 3:

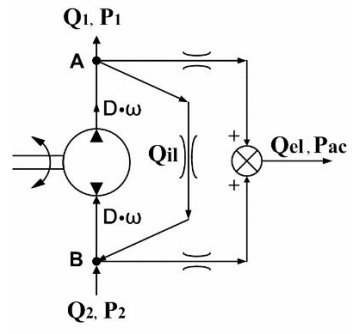

Figure 3: Diagram of pump, detailing the modeling of internal leakage. Source: [2].

The flow equation of nodes $\mathrm{A}$ and $\mathrm{B}$ are, respectively:

$$
\begin{aligned}
& Q_{1}=D \omega-Q_{i l}-Q_{e l 1}=D \omega-K_{i l p}\left(P_{1}-P_{2}\right)-K_{e l p}\left(P_{1}-P_{a c}\right) \\
& Q_{2}=D \omega-Q_{i l}+Q_{e l 2}=D \omega-K_{i l p}\left(P_{1}-P_{2}\right)+K_{e l p}\left(P_{2}-P_{a c}\right)
\end{aligned}
$$

Where $D$ is the displacement of pump, $K_{i l p}$ is the internal leakage coefficient of pump, $K_{e l p}$ is the external leakage coefficient of pump, $P_{a c}$ is the pressure of accumulator.

\subsection{Modeling of Refeeding Circuit}

The refeeding circuit, with an accumulator and check valves, is necessary to keep the pressure more stable in line and helps preventing cavitation. The schematic diagram is showed in Figure 4: 


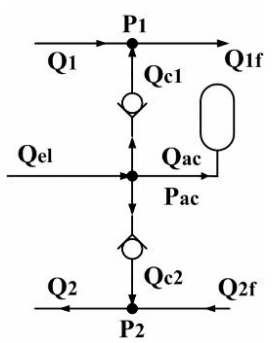

Figure 4: The refeeding circuit. Source: [2].

The flow equations in the refeeding circuit are:

$$
\left\{\begin{array}{l}
Q_{a c}=Q_{e l}-Q_{c 1}-Q_{c 2} \\
Q_{1 f}=Q_{1}+Q_{c 1} \\
Q_{2 f}=Q_{2}-Q_{c 2}
\end{array}\right.
$$

Where $Q_{e l}$ is the external leakage of pump, $Q_{c 1}$ and $Q_{c 2}$ are the flow of check valves depending on $\left(P_{1}-P_{a c}\right)$ and $\left(P_{2}-P_{a c}\right)$. The relationship between $Q_{a c}$ and $P_{a c}$ could be described as follows:

$$
P_{a c}=P_{a c i} V_{g a s i}^{k} /\left(V_{g a s i}-\int Q_{a c} d t\right)^{k}
$$

Where $P_{a c i}$ is the initial pressure of accumulator, $V_{\text {gasi }}$ is the initial volume of gas, $k$ is the polytropic exponent of gas within the range from 1.0 to 1.4.

\subsection{Modeling of Hydraulic Actuator}

EHA requires a symmetrical actuator in order to ensure flow balance between the actuator and the pump. The hydraulic jack shown in Figure 5 is divided into two working chambers by the piston.

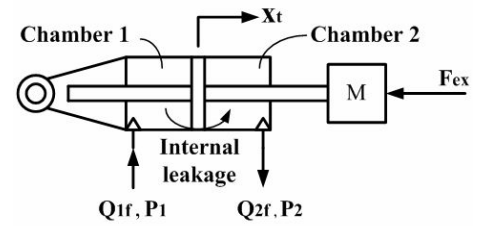

Figure 5: Hydraulic Actuator. Source: [2].

The flow in chamber 1 and 2 could be described by the following equations, respectively:

$$
\begin{aligned}
& Q_{1 f}=A \dot{x}_{t}+\frac{V_{10}+A x_{t}}{B} \dot{P}_{1}+K_{i l j}\left(P_{1}-P_{2}\right) \\
& Q_{2 f}=A \dot{x}_{t}-\frac{V_{10}-A x_{t}}{B} \dot{P}_{2}+K_{i l j}\left(P_{1}-P_{2}\right)
\end{aligned}
$$

Where $A$ is the active area of piston, $B$ is the bulk modulus of the hydraulic fluid, $K_{i l j}$ is the internal leakage coefficient of hydraulic jack, $V_{10}$ and $V_{20}$ are the initial volume of chamber 1 and chamber 2 respectively, which are the same in this symmetrical actuator. 
The load force balance equation of the piston is:

$$
A\left(P_{1}-P_{2}\right)=M \ddot{x}_{t}+F_{e x}
$$

Where $M$ is the total mass of piston and load, $F_{e x}$ is the external load force.

\subsection{Block Diagram of EHA Assembly}

Based on the sub-models described, an EHA without controller could be obtained. The block diagram in Figure 6 shows the interconnections of the sub-systems described previously and the top-level system visualization, where a very simple simple closed-loop control is done. The PID is basically a proportional gain. The inputs of the system are the displacement command to the actuator, and the external load. The outputs are the stroke position, stroke velocity and the motor current.

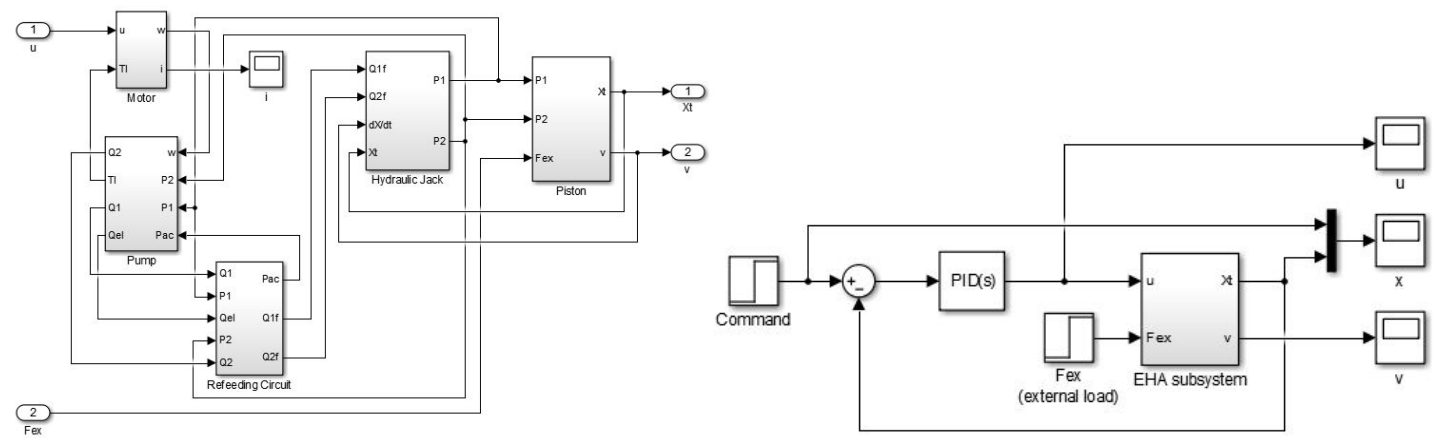

Figure 6: Interconnections of EHA model components in Simulink (left) and the block diagram of top-level closed-loop EHA system (right).

The system parameters are given in Table 1 .

Table 1: Parameters of EHA nonlinear models.

\begin{tabular}{|c|c|c|}
\hline Symbol & Description & Value \\
\hline $\mathrm{M}$ & Total mass of piston and load $[\mathrm{kg}]$ & 20 \\
\hline $\mathrm{L}$ & Motor winding inductance $[\mathrm{H}]$ & $2.5 \mathrm{E}-03$ \\
\hline $\mathrm{R}$ & Motor winding resistance $[\mathrm{Ohm}]$ & 1.5 \\
\hline $\mathrm{K}_{\mathrm{t}}$ & Motor torque constant $[\mathrm{N} \cdot \mathrm{m} / \mathrm{A}]$ & 0.2 \\
\hline $\mathrm{K}_{\mathrm{c}}$ & Motor speed constant $[\mathrm{v} /(\mathrm{rad} / \mathrm{s})]$ & 0.2 \\
\hline $\mathrm{J}$ & Total inertia of motor and pump $\left[\mathrm{Kg} \cdot \mathrm{m}^{2}\right]$ & $1.2 \mathrm{E}-03$ \\
\hline$K_{\text {fric }}$ & Sum of viscous coefficient of motor and pump $[\mathrm{N} \cdot \mathrm{m} /(\mathrm{rad} / \mathrm{s})]$ & 4.0E-04 \\
\hline $\mathrm{K}_{\mathrm{ilp}}$ & Internal leakage coefficient of pump $\left[\left(\mathrm{m}^{3} / \mathrm{s}\right) / \mathrm{Pa}\right]$ & $1.0 \mathrm{E}-13$ \\
\hline $\mathrm{K}_{\mathrm{elp}}$ & External leakage coefficient of pump $\left[\left(\mathrm{m}^{3} / \mathrm{s}\right) / \mathrm{Pa}\right]$ & $1.0 \mathrm{E}-13$ \\
\hline $\mathrm{K}_{\mathrm{ilj}}$ & Internal leakage coefficient of hydraulic jack $\left[\left(\mathrm{m}^{3} / \mathrm{s}\right) / \mathrm{Pa}\right]$ & $1.0 \mathrm{E}-13$ \\
\hline $\mathrm{D}$ & Pump displacement [ml/rev] & 1.2 \\
\hline $\mathrm{V}_{10}$ & Initial volume in chamber $1\left[\mathrm{~m}^{3}\right]$ & 152 \\
\hline $\mathrm{V}_{20}$ & Initial volume in chamber $2\left[\mathrm{~m}^{3}\right]$ & 152 \\
\hline A & Piston active area $\left[\mathrm{m}^{2}\right]$ & 19 \\
\hline $\mathrm{B}$ & Oil bulk modulus $\left[\mathrm{N} / \mathrm{m}^{2}\right]$ & $6.5 \mathrm{E}+08$ \\
\hline $\mathrm{V}_{\text {gasi }}$ & Initial volume of gas [ml] & 150 \\
\hline $\mathrm{P}_{\mathrm{aci}}$ & Initial pressure of accumulator [MPa] & 2.5 \\
\hline $\mathrm{k}$ & Polytropic exponent of gas [-] & 1.4 \\
\hline
\end{tabular}




\subsection{Physical modeling of EHA Assembly in AMESim}

Following the same Architecture shown in Figure 1, the EHA could be built also in AMESim, using the components library (See Figure 8). This model is prepared to be as equivalent as possible to the model obtained in Simulink, including the nonlinear effects of friction and saturation.

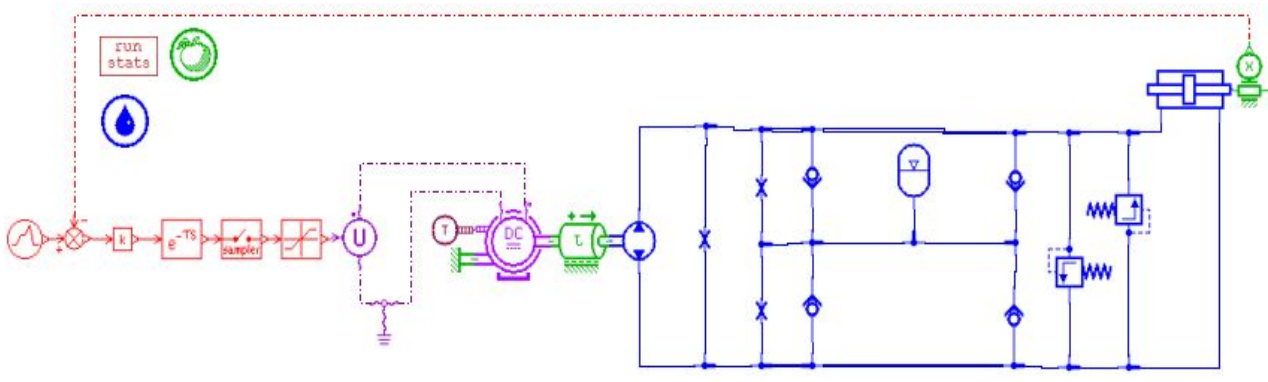

Figure 8: EHA full model in AMESim.

\section{Simulations}

In the Simulink and AMESim models of EHA, it was given a command of $10 \mathrm{~mm}$ displacement after 0.1 seconds the system is turned on.

The results of the Simulink model run are shown in the Figure 9, and AMESim model in Figure 10 .

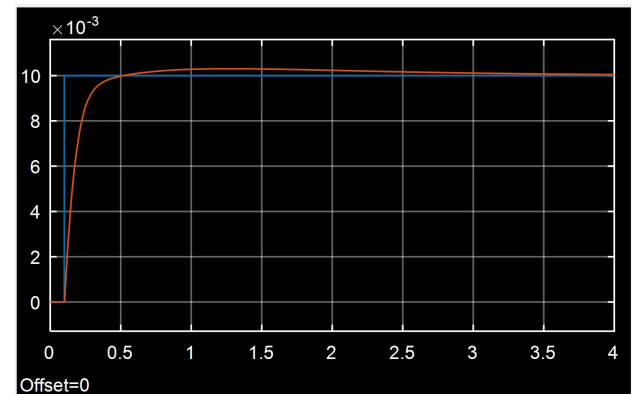

Figure 9: Displacement of EHA from Simulink model.

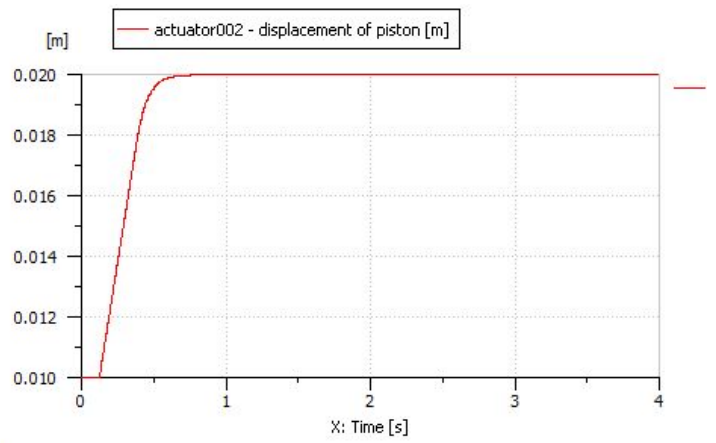

Figure 10: Displacement of EHA from AMESim model.

In the simulation results obtained from the Simulink model, made entirely with the mathematical equations turned into block diagrams, and the AMESim model, built entirely with components pre-modeled in the library, it is possible to observe that they show similar results in EHA performance, included an initial controller. The rise time of the piston displacement is very similar, around 0.5 second. After rise time, the piston position stabilizes at the commanded set point of $10 \mathrm{~mm}$ displacement.

However, the rate of piston observed in both simulations are not equal. A better tuning between these two models would probably lead to a better match. 


\section{Conclusions}

The preliminary results show that the EHA models in AMESim and Simulink provide similar responses and reasonable models matching. Using the 'physical modeling' approach, in AMESim, dispenses all the equationing and block diagrams of sections 2.1 through 2.6, to more easily and quickly obtain the model of the physical plant of the system. Following this approach still allows the user to perform the controller design in Simulink. This highlights the idea of integrating these both environments trough the AMESim-Simulink interface featured by AMESim, taking advantage of their combined characteristics.

\section{References}

[1] M. B. Gaïd, G. Corde, A. Chasse, B. Léty, R. De La Rubia, et al, Heterogeneous Model Integration and Virtual Experimentation using xMOD: Application to Hybrid Powertrain Design and Validation. 7th EUROSIM Congress on Modeling and Simulation, Prague, Czech Republic. pp.94-101, (2010).

[2] R. Kang, J Zongxia, S. Wu and J. Mare, The nonlinear accuracy model of electrohydrostatic actuator. Proceedings in: ROBOTICS, AUTOMATION AND MECHATRONICS, Beihang University, China. Chengdu: IEEE, p. 107-111, (2008).

[3] MOOG. Electrohydrostatic actuators homepage. [S. 1: s.n.]. Available at: $<$ http://www.moog.com/products/actuatorsservoactuators/actuationtechnologies/electrohy drostatic/>. Accessed on: Oct 12 ${ }^{\text {th }},(2015)$.

[4] PARKER HANNIFIN. Electro-hydrostatic actuators homepage. California, [s. n.]. Available at: $<$ http://ph.parker.com/us/en/electrohydrostatic-actuation-2684740electrohydrostatic-actuation-1>. Accessed on: Oct $20^{\text {th }}$, (2015).

[5] R. Sehab. An aerodynamic load for an electrohydraulic actuator: advanced modelling and implementation using electric actuators. Proceedings in: WORLD MULTICONFERENCE ON SYSTEMIICS CYBERNETICS AND INFORMATICS, 13, Orlando. p. 211-217, (2009).

[6] F. Xie, J. Wang, Y. Wang, Modelling and Co-simulation Based on AMESim and Simulink for Light Passenger Car with Dual State CVT. International Workshop on Automobile, Power and Energy Engineering, APEE, Wuhan, China, (2011). 